\title{
Towards a neuroscience of love: olfaction, attention and a model of neurohypophysial hormone action
}

\author{
Jan Havlicek ${ }^{1 *}$ and S. Craig Roberts ${ }^{2}$ \\ 1 Department of Anthropology, Charles University, Prague, Czech Republic \\ 2 School of Biological Sciences, University of Liverpool, Liverpool, UK \\ * Correspondence: jan.havlicek@fhs.cuni.cz
}

\section{A commentary on}

Romantic love modulates women's identification of men's body odors.

by Johan N. Lundström and Marilyn Jones-Gotman (2009). Horm. Behav. 55, 280-284.

The significance of odor in mediating affective state in humans has become increasingly recognized in recent years (Weber and Heuberger, 2008). In particular, human body odor or its constituent compounds influence general mood (e.g., Chen and Haviland-Jones, 1999), attentional state (Jacob et al., 2001) or proclivity toward other individuals, such as in a mate searching context (Saxton et al., 2008). Such effects are usually sex-specific, and women in particular appear more sensitive to, and cognizant of, olfactory cues (e.g., Havlicek et al., 2008).

In a recent paper, Lundström and JonesGotman (2009) used women's odor perception of male body odor as a novel approach for investigating the neurobiological basis of romantic love. Their idea was that the extent to which women could identify the body odor of partners compared with those of other men might shed light on the mechanisms underlying directed attention toward partners when in love. They tested the ability of 20 coupled women to recognize individual body odor using a threealternative forced-choice paradigm. Women were asked to identify their partner's axillary odor, or that of a male friend, from among three odors where the other two odors were of unfamiliar men. Separately, the women completed a psychometric instrument, the Passionate Love Scale, which estimates the degree to which they are in love with their partner. Women who scored highly on this scale were found to have lower success in identifying their male friends, but in contrast, there was no similar correlation for odor recognition of partners. There was also no similar correlation between their passionate love score and identification of female friends, indicating a sex-specific effect.

Lundström and Jones-Gotman argue that this specific reduction in recognition of opposite-sex friends supports the deflection theory for the psychological mechanism of romantic love. The deflection theory proposes that love is accompanied by a decrease in attention toward opposite-sex individuals, in contrast with an alternative idea which postulates intensified attention toward the romantic partner (although, as they acknowledge, these need not be mutually exclusive). Furthermore, they suggest a testable mechanism for this effect through antagonistic effects of the neurohypophysial hormones oxytocin and vasopressin, whereby elevated oxytocin levels, promoted by romantic love and attachment, causes a reduction in levels of bound vasopressin and an associated fall in attention toward individuals of the opposite sex.

The race is now on to test this intriguing hypothesis, and to examine whether the effect holds for male responses to female stimuli. Research in this area will also benefit from using tasks that measure verbalized hedonic perception or subliminal hedonic "decisions" manifested in affective change, in addition to those addressing cognitive processes such as verbal labeling and levels of olfactory recognition. Humans do indeed recognize their own odors, or those of partners, relatives and friends at levels higher than chance (Lenochova and Havlicek, 2008). However, level of performance is significantly lower compared to recognition based on visual appearance or voice: one can imagine how different our world would be if we misidentified our partner as often as one-half to two-thirds of the time (Hold and Schleidt, 1977). Use of hedonic rating scales, measurement of chemosensory event-related potentials (CSERPs) or functional neuroimaging would be illuminating; all these approaches have previously been successfully employed in tests of perception of bodily odors. For example, hedonic ratings (e.g., Roberts et al., 2008; Wedekind et al., 1995) and CSERPs (Krauel et al., 1998; Pause et al., 2006) have been used to explore relationships between genetic dissimilarity in potential mates in perception of axillary odors, while functional imaging has been used to investigate effects of 16androstenes, constituents of axillary odor (e.g., Gulyás et al., 2004). Through the use of such techniques, olfactory processing may hold the key to understanding the neuroscientific basis of love.

\section{REFERENCES}

Chen, D., and Haviland-Jones, J. (1999). Rapid mood change and human odors. Physiol. Behav. 68, 241-250.

Gulyás, B., Kéri, S., O’Sullivan, B. T., Decety, J., and Roland, P. E. (2004). The putative pheromone androstadienone activates cortical fields in the human brain related to social cognition. Neurochem. Int. 44, 595-600.

Havlicek, J., Saxton, T. K., Roberts, S. C., Jozifkova, E., Lhota, S., Valentova, J., and Flegr, J. (2008). He sees, she smells? Male and female reports of sensory reliance in mate choice and non-mate-choice contexts. Pers. Individ. Dif. 45, 565-570.

Hold, B., and Schleidt, M. (1977). The importance of human odour in non-verbal communication. $Z$. Tierpsychol. 43, 225-238.

Jacob, S., Kinnunen, L. H., Metz, J., Cooper, M., and McClintock, M. K. (2001). Sustained human chemosignal unconsciously alters brain function. Neuroreport 12, 2391-2394.

Krauel, K., Pause, B. M., Mueller, C., Sojka, B., MuellerRuchholtz, W., and Ferstl, R. (1998). Central nervous correlates of chemical communication in humans. Ann. N. Y. Acad. Sci. 855, 628-631.

Lenochova, P., and Havlicek, J. (2008). Human body odour individuality. In Chemical Signals in Vertebrates XI, J. L. Hurst, R. J. Beynon, S. C. Roberts and T. D. Wyatt, eds (New York, Springer), pp. 189-198. 
Lundström, J. N., and Jones-Gotman, M. (2009). Romantic love modulates women's identification of men's body odors. Horm. Behav. $55,280-284$.

Pause, B. M., Krauel, K., Schraders, C., Sojka, B., Westphal, E., Müller-Ruchholtz, W., and Ferstl, R. (2006). The human brain is a detector of chemosensorily transmitted HLA-class I-similarity in same- and opposite-sex relations. Proc. R. Soc. Lond., B, Biol. Sci. 273, 471-478.

Roberts, S. C., Gosling, L. M., Carter, V., and Petrie, M. (2008). MHC-correlated odour preferences in humans and the use of oral contraceptives. Proc. R. Soc. Lond., B, Biol. Sci. 275, 2715-2722.

Saxton, T. K., Lyndon, A., Little, A. C., and Roberts, S. C. (2008). Evidence that androstadienone, a putative human chemosignal, modulates women's attributions of men's attractiveness. Horm. Behav. 54, 597-601.

Weber, S. T., and Heuberger, E. (2008). The impact of natural odors on affective states in humans. Chem. Senses 33, 441-447.

Wedekind, C., Seebeck, T., Bettens, F., and Paepke, A. J. (1995). MHC-dependent mate preferences in humans. Proc. R. Soc. Lond., B, Biol. Sci. 260 245-249.

Received: 27 February 2009; published: 23 March 2009 Citation: Front. Evol. Neurosci. (2009) 1, 2. doi: 10.3389/neuro.18.002.2009

Copyright: (๑) 2009 Havlicek and Roberts. This is an openaccess publication subject to an exclusive license agreement between the authors and the Frontiers Research Foundation, which permits unrestricted use, distribution, and reproduction in any medium, provided the original authors and source are credited. 